\section{Cytoplasmic Particles in Bean Root Cells}

$I_{N}$ the course of an investigation of the composition of certain aqueous extracts of tissues from the bean root, the material was examined in an electron microscope. Small spherical granules, slightly smaller in size than the microsomes described by Claude ${ }^{1}$, Brachet and Jeener ${ }^{2}$, and Stern ${ }^{3}$, were detected. The size of the particles varied with the maturity of the tissue from which they were taken.

Bean seeds were germinated and sections cut from roots of standard length using the techniques previously described". Aqueous extracts were prepared from sections cut from the regions $0-2 \cdot 0 ; 7 \cdot 0-9 \cdot 0$; and $13 \cdot 0-15 \cdot 0 \mathrm{~mm}$. from the apex of the root. Each zone was cut into five $0 \cdot 4-\mathrm{mm}$. fragments. The groups of sections were placed in petrol ether, stored overnight at $+4^{\circ} \mathrm{C}$., and then washed, and ground with a glass pestle and mortar. $2.0 \mathrm{ml}$. of glassdistilled water was added and the resulting suspension centrifuged at approximately $5,500 \mathrm{~g}$ for $45 \mathrm{~min}$. Finally, the clear supernatant was diluted 5,000 times with glass-distilled water.

Silver-plated grids with 'Formvar' films were used as carriers in the electron microscope. A drop of fluid was transferred to the grid, and, after drying under reduced pressure in a vacuum desiccator over phosphorus pentoxide, the preparations were gold shadowed and examined in a Phillips electron microscope. Photographs were taken by Mr. G. W. Ripley at a magnification of $\times 20,000$. The particlesize was measured after projecting the electron micrographs on to a screen.

The accompanying photograph shows a typical electron micrograph of particles from the apical zone of the root. Measurements showed average diameters for the particles from the three zones of $0-2 \cdot 0,7 \cdot 0-9 \cdot 0$ and $13 \cdot 0-15 \cdot 0 \mathrm{~mm}$., of $37 \mathrm{~m} \mu, 24 \mathrm{~m} \mu$ and $20 \mathrm{~m} \mu$, respectively. Clearly, the particles are largest in the meristematic cells and tend to decrease in size as the cell matures. It was found that a similar change occurred when fragments are excised and cultured on water at $25^{\circ} \mathrm{C}$. for $48 \mathrm{hr}$. During culture the average diameter in tissue from the apical zone decreased from 36 to $28 \mathrm{~m} \mu$, and in the $13 \cdot 0-15 \cdot 0-\mathrm{mm}$. zone from 20 to $13 \mathrm{~m} \mu$.

Since particles similar to those described above have been found by earlier workers ${ }^{1-3}$ to be composed of ribonucleoprotein, the effects of trypsin, pepsin and ribonuclease on the bean root particles were investigated. Trypsin (B.D.H. reßgent) was used at a concentration of $1: 5,000$ in an extract adjusted to $p \mathrm{H} 8 \cdot 0$ with ammonium hydroxide; pepsin (B.D.H. reagent) at the same concentration but in an extract brought to $p \mathrm{H} 2 \cdot 0$ with hydro-

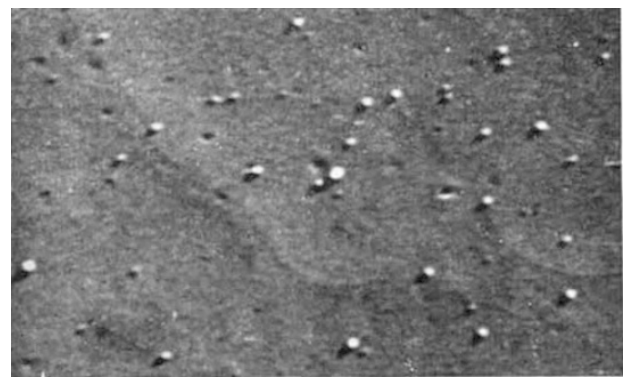

Electron micrograph of cytoplasmic particles in aqueous extract of region $0-2 \cdot 0 \mathrm{~mm}$. from apex of bean root. Magnification on print, $\times 30,000$ chloric acid; and ribonuclease (purified Armour Laboratories) at $1: 10,000$ in an untreated extract. Aliquots were incubated at $25^{\circ} \mathrm{C}$. for 3,8 and $21 \mathrm{hr}$. in each case with and without the enzyme. Extracts from the zone $0-2 \cdot 0 \mathrm{~mm}$. from the tip were used for these experiments.

With the exception of the extract treated with trypsin, particles were present in all preparations even after $21 \mathrm{hr}$. incubation. With trypsin there was little change during the first $3 \mathrm{hr}$., but a marked change after $8 \mathrm{hr}$. At the end of $8 \mathrm{hr}$. incubation the particles had almost entirely disappeared. A similar effect was observed in the extract treated for $21 \mathrm{hr}$. with trypsin. These observations suggest that the particles are composed of protein. The result with ribonuclease does not eliminate the possibility that they may also carry ribonucleic acid. If the skeletal framework is protein, removal of ribonucleic acid may not affect the overall size.

It is probable that the particles are structural components of the cytoplasm. Their significance in the metabolism of the cell is not yet known. It may be noted, however, that the change in size accompanies corresponding changes in the rate of increase of protein and in the activities of certain enzyme systems.

Further work on the chemical composition and metabolic activity of the particles is in progress, and a detailed account will be given elsewhere.

We thank Dr. R. D. Preston for facilities for using the electron microscope and Mr. G. W. Ripley for technical assistance.

Botany Department,

University, Leeds 2. Oct. 23.

${ }^{1}$ Claude, A., Science, 97, 451 (1943).

2 Brachet, J., and Jeener, R., Enzymologia, 11, 196 (1945).

${ }^{3}$ Stern, K., Cold Spring Harb. Symp. Quant. Biol., 7, 212 (1939).

Robinson, E., and Brown, R., J. Exp. Bot. (in the press).

\section{Effect of Thyroid Gland on the Cultivation of Amœba proteus}

A preliminary study of the effects of thyroid gland tablets on Amoba proteus, placod singly or in bulk in hollowed-out glass squares, having been made without any definite results, the whole of the resulting material was used for inoculating culture 12 , boiled wheat grains being the pabulum. For many month: the $p \mathrm{H}$ of this culture fluctuated around $p H 4$, and Euglena flourished. Bean and pea cotyledons were substituted as pabulum. Small amœbæ, length 10$20 \mu$, were now present in culture 12. Miguel's fluid was added and the $p \mathrm{H}$ rose to $p \mathrm{H} 6 \cdot 2$. After a few months had elapsod, adult $A$. proteus appeared, and culture 12 was so flourishing that it was divided up into sub-cultures. These cultures are readily distinguished from our stock cultures even by a biologist quite ignorant of their history by : (1) the larger size of the adult amœbæ in them, (2) the persistence of the adult stage beyond the normal span (the time occupied by the amobæ to grow from newly hatched to sporulation stage is twelve months); and, therefore, (3) the rarer occurrence of developmental stages in the culture; (4) difficulty in making successful sub-cultures from the original. 